\title{
Jogos fenício-púnicos
}

Maria Cristina Nicolau Kormikiari*

KORMIKIARI, M.C.N. Jogos fenício-púnicos. R. Museu Arq. Etn., 29: 112-118, 2017.

Resumo: Este texto procura abordar as parcas evidências, textuais e materiais, que possuímos acerca da existência de festividades religiosas que possam ser relacionadas a celebrações que envolvessem competições atléticas e/ou culturais dos povos fenícios.

Palavras-chave: Cartago; Fenícia; Festas religiosas; Jogos.

\section{Introdução}

Segundo Plutarco (Praecepta gerendae reipublicae, 3), o povo cartaginês

é amargo, taciturno, subserviente aos seus magistrados, severo com seus subordinados, absolutamente abjeto quando amedrontado, absolutamente selvagem quando irado, teimoso ao aderir às suas decisões, desagradável e duro em suas atitudes em relação ao divertimento e à urbanidade. Nunca, essas pessoas, se um Cleon as tivesse solicitado postergar uma assembleia porque havia feito um sacrificio e tinha convidados para entreter, teria adiado a reunião em meio a risos e palmas; nem teriam eles, quando uma codorma escapoliu de dentro do manto de Alcebíades no momento em que este

discursava, corrido avidamente para se juntarem à caça do animal para retorná-lo ao dono; não, eles teriam levado os dois à morte por sua insolência, tendo em vista que baniram Hannon sob a acusação de aspirar se tornar tirano, porque ele usava um leão, em suas campanhas

${ }^{*}$ Docente no Museu de Arqueologia e Etnologia - USP; pesquisadora do Labeca - Laboratório de estudos sobre a cidade antiga (MAE/USP). <tanit@usp.br> militares, para carregar suas coisas! (tradução nossa)

Esse imaginário de severidade estabelecido pela literatura greco-latina, do qual a passagem de Plutarco é o exemplo mais citado (cf. Dridi 2009: 223), acompanhada da gigantesca controvérsia em relação à questão do sacrifício infantil $1^{1}$, pode ser citado, em nosso entender, como uma não pouco significativa parte do desinteresse da academia em relação a aspectos do viver cotidiano e do viver social de fenícios, cartagineses e púnicos ${ }^{2}$.

É preciso ainda lembrar que não temos documentação textual primária substancial desses povos. Sabemos, por

1 Sobre o centenário debate acerca deste tema, ver Kormikiari (2017) e D'Andrea (2018).

2 Por fenício, entenda-se as populações das cidades-estado da costa Siro-Palestina, entre Tell Suqas (na atual Síria) e o Monte Carmel (no atual Israel), por exemplo Beirut, Tiro, Sarepta e Biblos, a partir da virada da Idade do Bronze para a Idade do Ferro; por cartaginês, os habitantes de Cartago, cidade de fundacão tíria (século IX a.C.), situada na atual Tunísia (Norte da África); e por púnico os diversos povos de colônias fenícias e cartaginesas do Mediterrâneo Centra (Norte da África; Sardenha; Sicília; Malta e ilhas próximas) e do Mediterrâneo Ocidental (Península Ibérica; Ilhas Baleares), que entraram, de maneira diferenciada, sob jugo cartaginês a partir do século VI a.C. (a partir de Kormikiari 2012; Moscati 1988). 
outras fontes, da existência de vasta literatura (mitológica, histórica e de temática variada), mas infelizmente não chegou até nós. Eventualmente, temos trechos de textos vertidos para o latim, como o tratado do agrônomo cartaginês Magon. Ele teria deixado uma obra com 28 livros salva do grande incêndio que devastou a capital africana em 146 a.C., quando os romanos a invadem durante a Terceira Guerra Púnica. Nada do original chegou até nós, mas em razão do grande interesse que o texto suscitava, o senado romano autorizou sua tradução para o latim; igualmente, foi realizada uma tradução para o grego. Estas duas traduções também não chegaram até nós. O que sobrou foi cerca de 40 citações. Todas falam de agricultura, arboricultura e administração de propriedades agrárias (Decret 1977: 87). Ou seja, a documentação textual, mesmo secundária, mais prolixa que temos sobre os cartagineses não nos fala sobre o tema de esportes, jogos, festividades religiosas a estes ligadas, e sim sobre economia.

De fato, a própria língua fenício-púnica é conhecida essencialmente a partir de documentação epigráfica, ou seja, inscrições majoritariamente sobre pedra e metal, de caráter principalmente oficial, e a vasta maioria destas possui caráter votivo e funerário. Temos algumas poucas exceções a este estado das coisas, com inscrições sobre fundações de localidades e inscrições tarifárias. Por outro lado, há a falta de textos poéticos, jurídicos, econômicos, hinos, preces, entre outros. Assim, o vocabulário que chegou até nós é reduzido, e a fraseologia é limitada. Inscrições sobre terracota (ostraca) e sobre papiros são raras.

Ainda assim, a documentação epigráfica é bastante vasta. Conta-se mais de $7 \mathrm{mil}$ inscrições descobertas em sítios fenício-púnicos, e Cartago é o local mais rico em relação a esse tipo de achado. Mesmo que, em sua imensa maioria, as inscrições estejam relacionadas à esfera da morte, mais especificamente ao tofet, o santuário a céu aberto, característico de alguns assentamentos púnicos no Mediterrâneo Central, onde ocorria, em paralelo a uma série de ritos de iniciação e cultos em pequenas capelas, o enterramento e/ou sacrifício infantil, é possível extrair informação pertinente ao tema deste artigo delas.

O que podemos entender como jogos? Como bem colocam Fábio Lessa e Renata C. de Sousa (2015: 73), os jogos, as competições esportivas, entre os helenos, eram também um meio de extroversão de um dos aspectos mais significativos desta sociedade, a competitividade (o agôn) $)^{3}$. No entanto, tampouco podemos esquecer outro aspecto essencial dos jogos antigos, o fato de estarem imbuídos de aspectos religiosos extremamente importantes, como não poderia deixar de ser, uma vez que uma das chaves essenciais para a compreensão do mundo antigo é o entendimento do imbricamento de todos os aspectos sociais, culturais, econômicos, políticos e religiosos (embeddedness, cf. Polanyi ${ }^{4}$ ).

Nesse sentido, tanto a ideia da competição como o aspecto religioso dos jogos serão as chaves de nossa abordagem do tema. A elas voltaremos adiante.

Uma nova geração de pesquisadores, como H. Dridi (2009: 223-230), mais recentemente vem afirmando que, mesmo não havendo à nossa disposição um conjunto expressivo documental, podemos afirmar que os cartagineses, ao menos os mais ricos, dedicavam-se aos exercícios filosóficos, à música, à poesia e praticavam atividades esportivas como a caça.

3 O arqueólogo Colin Renfrew (1986: 1-18) desenvolveu o conceito de peer-polity interaction para abordar processos de mudança social, cultural e política nas sociedades antigas, entre unidades políticas autônomas, como as pólis. A partir de relações igualitárias entre este tipo de unidade, mecanismos de competição, como os presentes em práticas esportivas e na própria guerra, o empréstimo de inovações tecnológicas (por meio do dom e do contradom; do comércio; e outras formas de troca), a adoção de estruturas simbólicas culturais (como crenças religiosas e abstrações normativas - a partir da existência de um vácuo a ser preenchido), levam ou aceleram processos internos de mudança societal dos participantes deste jogo de interações.

4 Karl Polanyi (1968), o grande nome do grupo substantivista, estava mais preocupado em entender o papel da economia nas sociedades antigas e em professar a impossibilidade de abordarmos tais sociedades sob o viés do desenvolvimento do mercado, apontando como a economia antiga encontrava-se submersa nas relações sociais e institucionais, incluindo-se aí, fortemente, a religião. No entanto, aqui queremos marcar a compreensão do imbricamento de todas as esferas no mundo antigo. 
A partir de dados epigráficos, verificamos que as cidades de origem fenícia, no Oriente e no Ocidente, possuíam um calendário de festas. A inscrição de Karatepe (KAI 26 A III 18) ${ }^{5}$ menciona um conjunto de festas que deveriam ser organizadas anualmente:

$\mathrm{C}$ Building the city and cultic innovations (II.9-III.2)

And I built this city.

And I gave it the name

Azatiwadaya,

since Ba'al and Reseph of the stags commissioned me to

build. So I built it,

by the grace of Ba'al and by the grace of Reseph of the stags, in abundance and in luxury and good living and in ease of heart, that it might be a guard (outpost) for the plain of Adana and for the house of Mopsos, since in my days there was for the land of the plain of Adana abundance and luxury.

And there was never any night for the Danunians in my days.

And I built this city.

And I gave it the name Azatiwadaya. I settled in it Ba'al KRNTRYS.

Now all the river-land shall offer a sacrifice to him:

a yearly sacrifice: an ox;

and at the time (season) of ploughing: a sheep;

and at the time (season) of reaping/ harvesting: a sheep

(Younger Junior 1998: 18-19)

Temos, assim, atestadas as festas do ano novo, da poda e da vindima em honra

5 Em meados do século XX (1946-7), uma inscrição hieroglífica bilíngue (luwian-fenício) foi descoberta nos ortostatos do portal da Idade do Ferro da fortificação de Karatepe, à margem esquerda do rio Ceyhan, na antiga região da Cilícia, moderna província de Adana, Turquia. Sua datação é do final do século VII ao início do século VIII a.C. à divindade Baal. $\mathrm{O}$ nome Baal é um nome semítico que significa "senhor", “dono". Em referência a uma divindade, esta denominação aparece 90 vezes no Antigo Testamento (como um nome específico de uma divindade canaanita). Apesar de haver um caráter apelativo, o nome é usado em ugarítico como o nome próprio de uma divindade ${ }^{6}$, onde aparece em mais de 500 referências (como uma divindade soberana, senhor das nuvens, das tempestades e dos raios). Ao longo do primeiro milênio a.C., Baal é o nome de um deus dos semitas e dos cananeus. A adoração a Baal claramente se espalha por toda a área habitada pelos cananeus. Durante o Reino Médio, o culto foi adotado pelos egípcios, em paralelo a outras divindades cananitas (Van der Toorn, Becking \& Van der Horst 1999: 132-3). A partir dos processos de expansão fenícia, eventualmente também se espalhou pela região mediterrânica, notadamente em Cartago, onde Baal presidia como Baal Hammon, junto à Tanit (Tanit ou Tinnit Pene Baal, literalmente "Tanit face de Baal"), as atividades centrais do tofet.

A área de domínio de Baal, a partir das inscrições, apresenta-se no genitivo, denotando posse. Assim, Baal é o senhor da montanha, de uma cidade (como no caso da inscrição de Karatepe, vista anteriormente), entre outras. Outra característica é a conexão deste lugar com um santuário dedicado à divindade (Van der Toorn, Becking \& Van der Horst 1999). Baal assegura prosperidade, vida e bem-estar, e a sucessão correta, cíclica, das estações. Suas

6 Ugarit (Antiguidade) ou Ras Shamra (modernamente) foi um importantíssimo porto cananeu, localizado ao sul da Síria, durante a Idade do Bronze. Por ocasião de uma das levas de invasão dos "Povos do Mar", foi totalmente destruída em torno do início do século XII a.C. A destruição pelo fogo permitiu, por outro lado, a preservação de milhares de tabletes de argila com registros em cuneiforme, encontradas nas escavações arqueológicas de quatro bibliotecas da cidade (do palácio, do templo e duas privadas). As línguas utilizadas são sumério, hurrita, acádio (idioma da diplomacia) e ugarítico. Os textos em ugarítico, que é uma língua semítica, trazem muita informação que, guardadas as devidas proporções, podem ser utilizadas para nossa compreensão dos fenícios. Particularmente, o panteão que aparece nos textos de Ugarit encontra uma continuidade em muitas cidades fenícias da Idade do Ferro. 
festas deveriam ser de extrema importância para a coesão societal.

Uma fonte escrita (Luciano, De Syria Dea, 6-9), datada do século II a.C., menciona as Adonias em Biblos, celebradas em 19 de julho $^{7}$. Estas festas em Biblos ocorreriam no templo de Astarté. O momento certo para o início dos ritos era assinalado pela chegada de uma mensagem enviada pelas mulheres de Alexandria e levada pelas ondas até o porto da cidade fenícia, apontando que Afrodite (Astarté) havia encontrado Adonis ${ }^{8}$. Um fenômeno natural, o "avermelhamento" do rio que nascia no Monte Líbano, acontecia no mesmo período e era interpretado como uma prova da morte de Adonis (De Syria Dea 6-7; Saint Cyril, Isa. 18:1-2; cf. Van der Toorn, Becking \& Van der Horst 1999: 7-9). O festival consistia em um período de luto geral, seguido de uma alegre proclamação de que "Adonis continua a viver", para além da morte. O herói recebia sacrifícios "como se estivesse morto", as mulheres ofereciam parte de seus cabelos e se dedicavam à prostituição sagrada (Ribichini 1984).

Por fim, temos ainda a menção a outra festa, a da égersis (morte e ressureição da divindade), como a de Melqart em Tiro, ocorrendo provavelmente entre janeiro e fevereiro. De fato, a documentação mais precisa

7 Adonis (originalmente "Senhor", cf. Hesíoquo s.v.) é um herói da mitologia clássica, amado por Afrodite e por Perséfone. Ele era objeto de um importante conjunto de celebrações em várias cidades do mundo antigo (notadamente em Atenas, Alexandria e cidades de Chipre) demonstrando, pelas descrições e menções às mesmas que chegaram até nós, que havia uma variedade regional do culto e de sua celebração. Adonis foi identificado com um deus fenício em Biblos, referido como DA.MU, nas cartas de Amarna (Van der Toorn, Becking \& Van der Horst 1999: 7-9).

8 De acordo com a tradição clássica, Adonis nasceu da união incestuosa entre a heroína Myrrha, que havia caído em desgraça junto à Afrodite, e seu próprio pai, Kinyras, rei de Chipre (ou da Assíria/Síria). Ele divide seu tempo entre os reinos dos vivos e o dos mortos. Tema central acerca de Adonis é o amor que por ele nutre Afrodite, e sua morte prematura; ele foi morto por um javali enquanto caçava. As histórias de seu amor e de sua morte são os temas dos festivais Adonias, celebrados na Atenas Clássica, na Alexandria Ptolomaica e no mundo romano. Além do ritual de velar o corpo, havia outros ritos que variavam dependendo da região e do período (Ribichini 1984). relacionando uma festividade religiosa à prática de competições esportivas vem dessa celebração.

O significado do nome Melqart é "rei da cidade", de $m l k$, rei, e qart, cidade, em fenício. Neste sentido, essa divindade aparece indelevelmente ligada às cidades fenícias e púnicas. No entanto, Sergio Ribichini, em seu verbete sobre essa divindade, nos lembra que ela possuía, também, um profundo caráter ctônico, de modo que o termo qart poderia igualmente ser interpretado como eufemismo para submundo, denominado a "grande cidade" na tradição mesopotâmica (Van der Toorn, Becking \& Van der Horst 1999: 563).

Melqart é, ainda, identificado com o herói grego (ou com o romano) Héracles/Hércules, tendo a característica de uma divindade citadina; seus mitos o apresentam como um herói (Bonnet 1988: 399 e seguintes). Uma inscrição bilíngue de Malta (KAI 47), do século II a.C., o denomina "Baal de Tiro", ou seja, o "herói tutelar"; o "ancestral epônimo" de sua cidade (Van der Toorn, Becking \& Van der Horst 1999: 564) $)^{9}$.

Uma fonte textual importante sobre o culto de Melqart é Heródoto (II 44). O autor grego nos informa que as pessoas de Tiro prestavam homenagem à divindade como se ela fosse um herói, como alguém que havia morrido, isto é, que originalmente havia sido mortal. Menandro de Éfeso (citado por Flávio Josefo, Ant. Jud., VIII, 146) relata como Hiram, rei de Tiro contemporâneo a Salomão, mandou derrubar templos antigos e colocou nos seus lugares novos, em honra a Héracles e a Astarté. O mesmo rei teria sido o primeiro a celebrar o despertar (égersis) de Héracles no mês peritios (fevereiro-março). Outras fontes mencionam o seu festival anual, que traz semelhanças a cultos análogos de divindades que morrem e renascem (por exemplo, Adonis e Eshmun).

Serge Ribichini acredita que esse festival anual deveria ser o maior dedicado a Melqart:

9 A documentação epigráfica, arqueológica e textual mostra como Melqart teve um papel fundamental na expansão fenícia para o ocidente mediterrânico. Seu culto foi popular em diversas cidades dessa diáspora: de Chipre à Malta; do Norte da África, à Sicília, Sardenha e Península Ibérica (Van der Toorn, Becking \& Van der Horst 1999). 
a divindade, morta pelo fogo, renascia a partir de um casamento sagrado com Astarté (Van der Toorn, Becking \& Van der Horst 1999: 564).

Por fim, de particular interesse para nossa discussão nesse espaço é a informação contida em II Macabeus 4:18-20, a qual relata que, ao longo do século II a.C., a cada cinco anos, jogos eram celebrados em Tiro em honra ao herói local, Héracles, isto é, Melqart (Van der Toorn, Becking \& Van der Horst 1999: 565) ${ }^{10}$. Muito provavelmente, o rei estava presente nesses jogos, com povos e governantes de estados vizinhos, trazendo presentes. Sacrifícios seriam realizados na ocasião (Bonnet 1988: 57-58).

Documentos epigráficos encontrados em assentamentos de Chipre mencionam outras festividades religiosas, como as da lua cheia e da lua nova (a do mês do sacrifício a Shamash era particularmente frequentada). No Pireu, uma inscrição bilíngue menciona uma festa do Mrzh, durando ao menos quatro dias, talvez cinco. Uma inscrição fragmentada menciona uma festa em Cartago que durava, ao menos, cinco dias (Dridi 2009: 224).

Pensando a relação entre celebração religiosa e os jogos, tão fortes no mundo grego em certas ocasiões, não seria improvável que as festas mencionadas pudessem conter práticas de competição entre a aristocracia.

As fontes escritas levam a entender que os fenícios eram pouco entusiastas de jogos públicos. No entanto, podemos pensar que os jogos cartagineses eram diferentes dos jogos gregos e romanos. Alguns estudiosos como H. Dridi (2009) pensam que, em conexão com sua origem oriental, as praças públicas de Cartago recebiam acrobatas, demonstrações de força e domadores de animais. Plínio, o velho (HN, VIII, 55), menciona um Hannon, que caçava e aprisionava

10 O século II a.C. é um momento de presença e força selêucida na região. As cidades fenícias, antes divididas pelas lutas dos diádocos, agora parecem homogeneizar-se, ao menos as elites. Percebe-se um aumento do uso do alfabeto grego e a adoção de cultos de origem grega, incluindo jogos em honra às divindades (Baslez e Briquel-Chatonnet 2003: 206-210). Devemos, claro, levar essa questão em consideração e não concluir que temos aqui uma comprovação de que os fenícios realizavam jogos aos moldes gregos em períodos anteriores. leões, o que the havia dado o codinome de “domador de leões" (Dridi 2009: 226).

\section{Altar dos Philaeni (Arae Philaenorum)}

Por fim, falaremos do Altar dos Philaeni ${ }^{11}$. Trata-se de um monumento que teria sido erigido em honra a dois irmãos cartagineses nos confins da Tripolitânia, isto é, na fronteira com a Cirenaica (as duas regiões estão localizadas, hoje em dia, na Líbia). A história foi narrada, primeiramente, por Salústio (Guerra de Jugurta, 79), mas a historiadora Josephine Crawley Quinn (2014: 169 e seguintes) defende que esta lenda não se trata de uma criação grega, e sim, de fato, teria se originado a partir de uma fonte cartaginesa refletindo afirmações territoriais cartaginesas na área, do século III e/ou início do II a.C. A versão cartaginesa reverte estereótipos nascentes greco-romanos sobre os cartagineses (a noção da punica fides - falta de fé púnica), bem como "normas míticas" gregas.

Salústio nos informa (tradução nossa):

Quando os cartagineses governavam sobre a maior parte da África, o povo de Cirene também era forte e próspero. Entre as duas cidades estirava-se uma planície de areia sem fim, sem rios ou montanhas para marcar uma fronteira, circunstância que envolveu os dois povos em uma longa e amarga rivalidade. Depois que muitos exércitos e frotas tivessem sido derrotados e postos a correr pelos dois lados da contenda, e eles tivessem infligido danos consideráveis uns aos outros... eles chamaram uma trégua, na qual chegaram ao seguinte arranjo. Em um dia acertado, enviados de cada cidade deveriam partir de seus lares, e o

11 Pseudo-Cílax (Périplo, 109), no século IV a.C., assinala um santuário de Amon próximo às Arae Philaenorum, marcando o caráter sagrado da região. Identificado por Goodchild (1952: 95-97 apud Crawley Quinn 2014: 171) com base nas distâncias apresentadas nas fontes como o promontório de Ras el Aáli, a $129 \mathrm{~km}$ de Cirene e $180 \mathrm{~km}$ de Cartago. Esta área é muito plana, e justamente nessa localização, para o interior há a visão, do mar, do cume de Jebel Ala. É possível que estes fossem, de fato, os "altares" originais. 
ponto onde se encontrariam seria considerado a fronteira comum (finis) dos dois povos. Cartago mandou dois irmãos, chamados Philaeni, que se apressaram; os de Cirene foram mais devagar. Quando estes descobriram que estavam muito atrás, acusaram os cartagineses de terem deixado sua terra muito antes do combinado e contestaram o resultado. Os cartagineses demandaram outros termos, desde que fossem justos, e os gregos lhes deram a chance de serem enterrados vivos no local que desejassem fixar a fronteira, ou de deixarem eles, na mesma condição, avançarem o tanto que desejassem. Os Philaeni aceitaram os termos e entregaram suas vidas à sua terra; e então foram enterrados vivos. Os cartagineses dedicaram altares aos irmãos Philaeni naquele local, e outras honras lhes foram dadas em sua cidade (Guerra de Jugurta, 79).

Segundo Ptolomeu (4.3.4), Philaenus era o nome de um vilarejo (kome), perto do qual estavam os altares com o mesmo nome. É possível que estes tenham recebido seu nome do vilarejo, o qual, por sua vez, recebeu o nome de um proprietário grego, prática normal na região (Crawley Quinn 2014: 171).

Na opinião de Crawley Quinn (2014: 172-173), devemos trabalhar com a hipótese da história narrada por Salústio ter uma origem cartaginesa. Os argumentos utilizados pela historiadora são dois: o fato de os heróis do enredo serem cartagineses e Salústio afirmar em seu texto ter usado fontes norte-africanas e não gregas.
O ponto que nos interessa aqui é a força atlética dos heróis cartagineses. Partindo do pressuposto de estarmos lidando com uma construção lendária, criada em ambiente norteafricano, púnico ou cartaginês, de legitimação de uma vasta área territorial, temos que o ato heroico de entregar a própria vida para salvar a honra de Cartago teve como causa principal a enorme vantagem que os corredores cartagineses obtiveram na disputa com os de Cirene. Isto é, eles foram os vencedores na corrida.

Teríamos aí uma prova, mesmo que circunstancial, de que a corrida fizesse parte das práticas aristocráticas cartaginesas?

\section{Conclusão}

Acreditamos ser difícil projetar, para o mundo fenício-púnico, práticas atléticas e competitivas similares aos jogos gregos e mesmo os posteriores romanos. No entanto, acreditamos ser absolutamente plausivel trabalhar com os poucos indícios textuais arrolados em nosso texto para vislumbrar a existência, nas cidades fenícias e púnicas, de práticas celebrativas nas quais a exibição de destreza e força atlética estivessem presentes, prática essa a ser relacionada à aristocracia.

O presente texto é uma pequena introdução ao tema, o qual se apresenta como interessante questionamento a ser aprofundado a partir de um estudo comparativo da documentação escrita e material do mundo fenício-púnico.

KORMIKIARI, M.C.N. Phoenician-Punic games. R. Museu Arq. Etn., 29: 112-118, 2017.

Abstract: This text addresses the analysis of the meager textual and material evidence available regarding the existence of religious festivities that might be related to celebrations encompassing athletic and/or cultural contests among the Phoenician people.

Keywords: Carthage; Phoenicia; Religious celebrations; Games. 


\section{Referências bibliográficas}

Baslez, M.-F.; Briquel-Chatonnet, F. 2003. Les Phéniciens dans les royaumes hellénistiques d'Orient (323-55). In: Le Dinahet, M.T. (Org.). L'Orient méditerranéen de la mort d'Alexandre au ier siècle avant notre ère. Anatolie, Chypre, Égypte, Syrie. Éditions du Temps, Nantes: 197-212.

Bonnet, C. 1988. Melqart. Cultes et mythes de l'Héracles tyr ten en Méditerranée. Studia Phœnicia 8 , Bibliothèque de la Faculté de Philosophie et Lettres, Namur, v. 69.

Crawley Quinn, J. 2014. A Carthaginian Perspective on the Altars of the Philaeni, In: J. C. Quinn e N. C. Vella (eds.), The Punic Mediterranean: identities and identification from Phoenician settlement to Roman rule: 169-179.

D’Andrea, B. 2018. Bambini nel 'limbo'. Dati e proposte interpretative sui tofet fenici e punici. Collection de l'École Française de Rome, 552.

Decret, F. 1977. Carthage ou l'empire de la mer. Éditions du Seuil, Paris.

Dridi, H. 2009. Carthage et le monde punique. Guide Belles Lettres des Civilisations. Les Belles Lettres, Paris.

Heródoto. 1989. Histoires. Ph. E. Legrand (Ed.). Les Belles Lettres, Paris.

Josefo, Flávio. 2006. Jewish antiquities (Ant. Jud.). W. Whiston (tradução). Wordsworth Editions, London.

Kaih, D.; W. Röllig. 1962-1964. Kanaanaische und Aramaische Inschriften, Band I - III, Wiesbaden. Edição revisada 1966-1969.

Kormikiari, M.C.N. 2012. Movimentação feníciopúnica no Mediterrâneo Ocidental: novas perspectivas a partir dos estudos em Arqueologia da Paisagem. MARE NOSTRUM: História e Integração no Mediterrâneo Antigo 3: 138-156.

Kormikiari, M.C.N. 2017. O papel de Cartago no debate acerca do sacrifício humano fenício-púnico. Romanitas: Revista de Estudos Grecolatinos 10: 100-122.

Lessa, F.S.; Sousa, R.C. 2015. O agôn esportivo na cerâmica ática do período clássico. Phoînix 21(1): 72-85.

Luciano. 2003. On the Syrian Goddess (De Syria Dea). J. L. Lightfoot (tradução e comentários). Oxford University Press, Oxford.

Moscati, S. 1988. Fenicio o punico o cartagines. Rivista di Studi Fenici 16: 3-13.

Plutarco. 1936. Praecepta gerendae reipublicae. Harvard, Loeb Classical Library, v. X.

Polanyi, K. 1968. Primitive, Archaic and Modern Economies. In: Dalton, G. (Org.). Ensaios. Beacon Press, Boston.

Pseudo-Cílax. 1883. Périplo. In: Müller, C. (Ed.) Geographi Graeci minores. Paris, 1855, v. I, 85.

Ptolomeu. Geographia. Alfredo Firmin Didot, Paris.

Renfrew, C. 1986. Introduction. In: Renfrew, C.; Cherry, J.F. (Eds.) Peer Polity Interaction and Socio-Political Change. New Directions in Archaeology, Cambridge University Press, Cambridge: 1-18.

Ribichini, S. et al. 1984. Adonis. Relazioni del Colloquio in Roma (1981). Collezione di Studi Fenici, 18, Roma, C.N.R.

Saint Cyril. 2014. The Catechetical Lectures of St. Cyril of Jerusalem. In: Boer, P.A. (Ed.). Veritatis Splendur Publications, Rome.

Salústio. 1991. Guerra de Jugurta. J. M. Pabón (tradução). 3. ed. Consejo Superior de Investigaciones Científicas, Madrid.

Van der Toorn, K.; Becking, B.; Van der Horst, P.W. 1999. Dictionary Of Deities And Demons in the Bible. 2. ed. Brill Publishers, Leiden, Boston, Köln.

Younger Junior, K.L. The Phoenician inscription of Azatiwada. An integrated Reading. Journal of Semitic Studies XLIII(1): 11-46. 